\title{
UNIVERSITYOF
}

FORWARD

THINKING

WESTMINSTER用

WestminsterResearch

http://www.westminster.ac.uk/westminsterresearch

\section{Agent-Based Modeling of Deshopping Behaviour: A Single Shop Model with Multiple Deshoppers}

Rahman, S. and Li, Shuliang

This is a copy of the author's accepted version of a paper subsequently published in the proceedings of the 2nd International Conference on Information Management (ICIM2016) London, 7-8 May 2016 by IEEE.

The final, definitive version is available online at:

\section{http://dx.doi.org/10.1109/INFOMAN.2016.7477539}

(C) 2016 IEEE . Personal use of this material is permitted. Permission from IEEE must be obtained for all other uses, in any current or future media, including reprinting/republishing this material for advertising or promotional purposes, creating new collective works, for resale or redistribution to servers or lists, or reuse of any copyrighted component of this work in other works.

The WestminsterResearch online digital archive at the University of Westminster aims to make the research output of the University available to a wider audience. Copyright and Moral Rights remain with the authors and/or copyright owners.

Whilst further distribution of specific materials from within this archive is forbidden, you may freely distribute the URL of WestminsterResearch: ((http://westminsterresearch.wmin.ac.uk/)).

In case of abuse or copyright appearing without permission e-mail repository@westminster.ac.uk 


\section{Agent-Based Modeling of Deshopping Behavior: A Single Shop Model with Multiple Deshoppers}

\author{
SHAWKAT SALIM RAHMAN \\ Westminster Business School, \\ University of Westminster, \\ 35 Marylebone Road, London NW1 5LS, \\ UNITED KINGDOM \\ shawkat.rahman@my.westminster.ac.uk
}

\author{
SHULIANG LI ${ }^{1,2, *}$ \\ ${ }^{1}$ Westminster Business School, \\ University of Westminster, \\ 35 Marylebone Road, London NW1 5LS, \\ UNITED KINGDOM \\ lish@westminster.ac.uk \\ ${ }^{2}$ School of Economics \& Management, \\ Southwest Jiaotong University, \\ Chengdu, Sichuan 610031, CHINA
}

\begin{abstract}
Deshopping is rapidly turning into a modern day scourge for the retailers worldwide due to its prevalence and regularity. The presence of flexible return policies have made retail return management a real challenging issue for both the present and the future. In this study, we propose and develop a multi-agent simulation model for deshopper behavior in a single shop context. The background, theoretical underpinning, logical and computational model, experiment design and simulation results are reported and discussed in the paper.
\end{abstract}

Keywords - deshopping; simulation; multi-agent system; logistics; retail marketing; software agent

\section{INTRODUCTION}

Liberal return policies are both a prerequisite and a legal requirements in today's retail business environments. Marketing literature suggests close link between liberal return policies and long term competitive and financial benefits [1]. Certain intersections of customers are thriving in this environment of liberal return policies. These customers are delaying the actual purchase decision until after having experienced or used the product. Returning the products allows them to reverse the purchase decision [2]. The retailer 'Montgomery Ward' first instituted liberal return policies in their chain stores in 1880 . These policies were put in place to provide retailers with an opportunity to cultivate long term competitive advantage [3].

Deshopping is considered in retail marketing literature to be abuse of return policy. It has also been introduced under a broad umbrella of terms such as retail borrowing [4], Jay customers [1], fraudulent borrowing [5], unethical retail disposition [3], wardrobing, free customer rentals, fraudulent return, and boomerang shopping among others in retail marketing literature [6]. Schmidt et al. [7] labelled deshopping as the "deliberate and arguably inappropriate return of goods for reasons other than actual faults in the product". This unethical behaviour is forcing retailers with illicit product returns and unwanted inventories in both forward/reverse supply chains $[8,9,10,11]$. Retailers consider fraudulent returns to erase 10\%-20\% from profit margin [12].

Retailers and researchers reported that the total value of retail shrinkage in 2003 was 27,258 million pounds [13]. Research indicates about $20 \%$ returns in retail landscape are deshopped products [3]. This includes a sizeable amount of deshopped merchandise. Ironically, despite its quasicriminal nature, deshopping is only considered $4^{\text {th }}$ (out of 15) worst ethically questionable consumer behaviour by consumers [5]. Ironically, deshopping is considered less intrusive and destructive than other forms of unethical shopping norms. However, it can create huge pressure on both the retail environment and reverse logistics structure of firms with products returns [9].

Deshopping remains under researched in retail marketing, strategy, simulation and modeling based research/analysis. The current deshopping related research is based on a number of theories in multi-disciplinary perspectives such as marketing [3], retail marketing management $[2,4,9,13,14]$ behaviour and intention theories [15, 16, 17] and ethics [18].

\section{The DeshopPING PROCESS}

Schmidt et al. [7] considered the financial and risk reduction aspects that triggered deshopping and proposed a framework which combines the demographic characteristics and psychographic factors of deshoppers. It also illustrates the relationships and associations between the factors.

Consumer research has been centred on the consumer's acquisition and consumption stages and not much at all on the disposition stage. Most of the disposition research has covered the sunnier side of disposition options such as gift giving, recycling, and online and offline auctions. All these options fail to consider the darker side of consumer disposition [6] which is essentially deshopping.

According to Rosenbaum, Kuntze and Woodridge [19], deshopping shows the following characteristics: 1. The product must be purchased and subsequently returned at a later date for a full refund. 2. The purchaser must have 
received some value from the product prior to return and refund. 3. The product does not possess any actual defects. 4. The purchaser must decide on the return before, during or after purchase. 5. The purchaser must be aware that he/she is taking advantage of the retailers return policy.

Marketing literature has provided considerable attention to consumer decision making models in both research and practice. The five stage consumer decision making process model forwarded by [20] provided the ideal background for consumer behaviour. This process model illustrates that all consumer behaviours are planned behaviours; they are reasoned actions [21]. This line of research follows smoothly into planned behaviour which is the driving force behind consumer decision process.

The behavioural intention theory used to analyse deshopping behaviour of consumers was refined by King, Dennis and Wright [2]. Mitchell et al. [22] measured unethical consumer behaviour across four countries using index of unethical consumer behaviour tailored for deshopping activities. Since then Muncy and Vittel [23] index of unethical consumer behaviour scale has since been updated to reflect newer retailing scenarios.

The retail marketing environment can be viewed as a complex adaptive system with its network of interacting agents such as the regulations, competing firms, shoppers, etc. [24]. The deshopping environment can be built as a complex adaptive system populated by the deshoppers, firms, competition, regulations etc. These agents can be adaptive and attempt to maximize its assigned value over time. These models also provide a large degree of control [25].

The simulation method can be very useful for deshopping analysis. Simulation with "what-if" analysis and dynamic graphical displays can provide an enriched experience. Simulation with graphical animation has the advantages of being able to provide system behaviour depiction, information communication, visual interaction, simulation realism and decision support [26]. Simulation based analysis can also depict deshopping scenarios for debate and analysis[1].

\section{ThE COMPUTATIONAL MODEL FOR DESHOPPING}

The focus of our research is to propose and develop an agent-based model for deshopping behavior of consumers in a simulation modeling environment. The model includes elements of the retail environments such as deshoppers, businesses, shoppers, etc.

Rapid development of theory and applications based upon multi-agent systems have revolutionized the research approach towards complex economic and business systems [27]. Most of these systems are complex dynamic systems.
The modeling approach for our complex systems is agentbased approach.

Simulation allows business processes to be modelled, better understood and has the potential to make improvements without incurring the traditional risks [15].

The theoretical underpinnings of the deshopping model is based on prior research carried out by Rahman and Li [1] and theory of crime [ 27].

In our computational modeling, we consider deshopping as a social dilemma scenario - a 'tragedy of the commons'. This makes it possible to describe and represent deshopping as a crime and model its payoffs as such.

In the presence of easy return policies, let us consider

Reward from Deshopping to be - $g$

If a deshopping/ return attempt is rejected then the Cost of deshopping becomes $\mathrm{f}$ - cost of deshopping attempt and $\mathrm{p}$ - chance of being caught.

Thus, Cost of Deshopping comes to $-\mathrm{p} * \mathrm{f}$

In order for deshopping to be less appealing

$$
g-p * f<0
$$

Where g can be further broken down into: Utility of usage $(\mathrm{u})$; Peer approval through concept transmission $(\mathrm{t})$; Funds reuse (m).

These are consistent with the literature on deshopping and what motivates deshoppers [12].

Costs can be defined as the following: Cost of item c; Opportunity cost v; Enforcement cost gc.

Thus the deshopping equation becomes

$$
g(u+t+m)-p F(c+v+g c)<0
$$

This controls the motivation, loyalty and persistence of a deshopper to continue with continued deshopping attempts.

\section{THE Simulation MODEL}

The retail marketing environment can be viewed as a complex adaptive system with its network of interacting agents such as the regulations, competing firms, shoppers, etc. [28].

The deshopping environment can be built as a complex adaptive system populated by the deshoppers, firms, competition, regulations etc. These agents can be adaptive and attempt to maximize its assigned value over time. These models also provide a large degree of control [ 4, 29].

Our iteration interface as illustrated in Fig 1 has the following improvements: making consumer deshopping behaviour as the central tenant of the model, and using pseudo random seeds for reproducibility. 

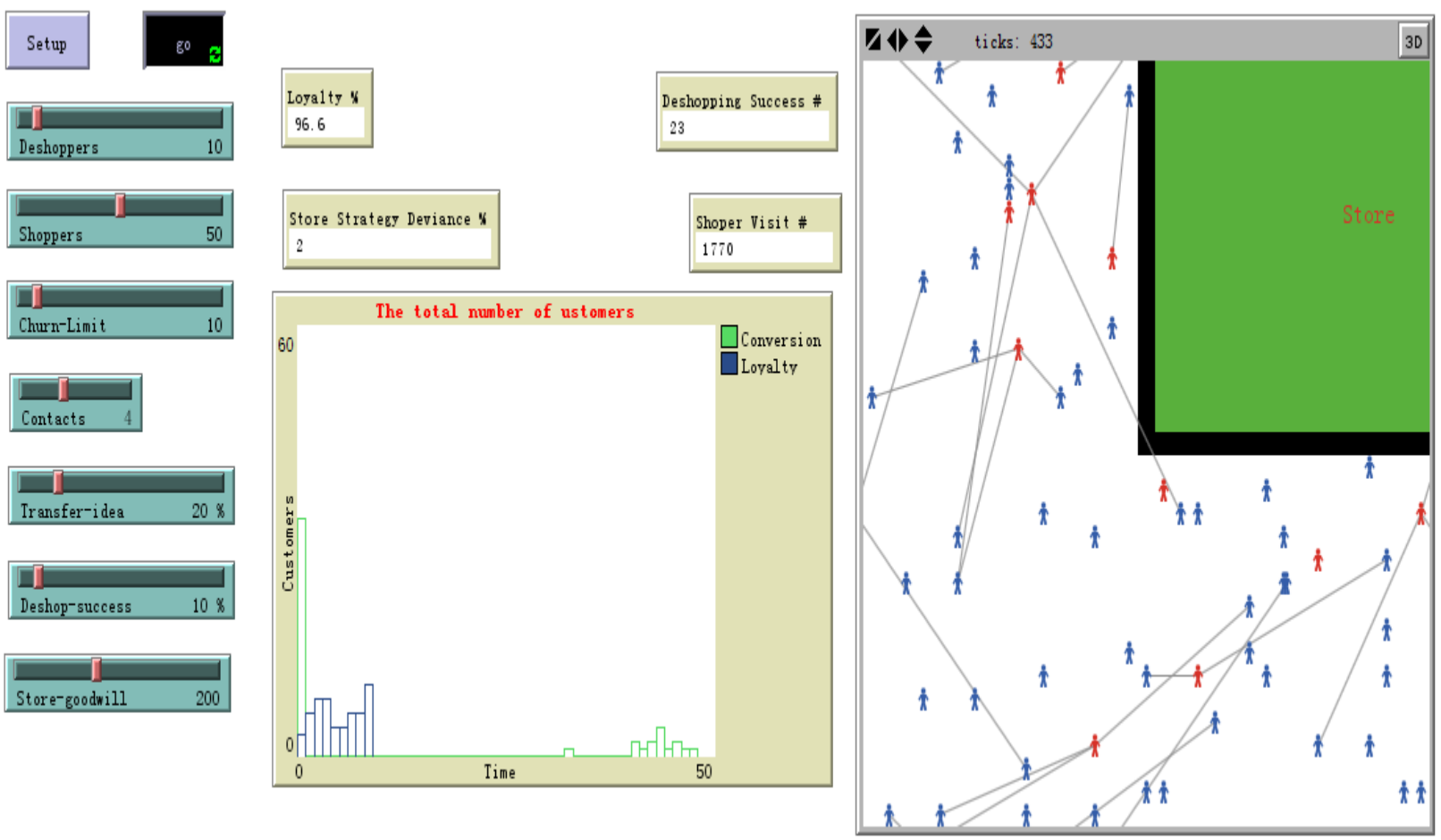

Fig 1: The interface of deshopping modeling

The logic flow of the model consists of the following steps.

Step 1 sets up the parameters of the model and initializes Global Variables. Step 2 initialises Turtle Variables. Next on Step 3, the deshopper turtles link with a set of turtles to form its own group. These are the turtles to whom it can pass deshopping concepts. In Step 4, Turtles start on the Real World designated by the White Patch. They move around randomly. In Step 5 the turtles visit the Store designated by the green patch.

Once on the green patch, Deshoppers try to return products and shoppers try to buy products. Then they return to the shop world and renews the process. In Step 6, if the deshoppers fail to return then its loyalty is reduced. If it falls below Threshold, then it dies. And this means that the store has lost a shopper forever.

\section{THE EXPERIMENTAL DESIGN AND RESULTS}

The experiment will contain ten computational scenarios that will simulate the spread of deshopping and its impact on a business's consumer base.

We will compare scenarios where Deshopper numbers vary. Table I holds the data from the simulation runs.

By analyzing the data from the experiments, we can see from Fig.2 that the deshopping success grows as Deshopping Success $\%$ grows and losses are greater and store strategy suffers. This obviously hurts both the bottom line and goal alignment. 
TABLE I. DATA FOR SCENARIO COMPARISON

\begin{tabular}{|c|c|c|c|c|c|c|c|c|c|c|c|c|c|}
\hline & \multicolumn{7}{|c|}{ Simulation Parameters } & \multicolumn{4}{|c|}{ Results } & & \multirow[b]{2}{*}{$\begin{array}{l}\text { Deshooper } \\
\text { /Shopper } \\
\text { Ratio }\end{array}$} \\
\hline $\begin{array}{l}\text { Exp } \\
\# \\
\end{array}$ & $\begin{array}{l}\text { Deshopper } \\
\#\end{array}$ & $\begin{array}{l}\text { Shopper } \\
\#\end{array}$ & $\begin{array}{l}\text { Churn } \\
\text { Limit }\end{array}$ & $\begin{array}{l}\text { No of } \\
\text { Contacts }\end{array}$ & $\begin{array}{l}\text { Transfer } \\
\text { Idea \% }\end{array}$ & $\begin{array}{l}\text { Deshop } \\
\text { success } \\
\%\end{array}$ & $\begin{array}{l}\text { Store } \\
\text { Goodwill }\end{array}$ & Loyalty & \begin{tabular}{|l} 
Store \\
Strategy \\
Deviance
\end{tabular} & $\begin{array}{l}\text { Deshopping } \\
\text { Success }\end{array}$ & $\begin{array}{l}\text { Shopper } \\
\text { Visits }\end{array}$ & $\begin{array}{l}\text { Deshopping } \\
\text { attempt/ } \\
\text { Shopper } \\
\text { visits Ratio }\end{array}$ & \\
\hline 1 & 10 & 50 & 10 & 4 & $20 \%$ & $10 \%$ & 200 & $86.80 \%$ & $2.50 \%$ & 37 & 1830 & $2.02 \%$ & 0.2 \\
\hline 2 & 10 & 50 & 10 & 4 & $20 \%$ & $40 \%$ & 200 & $88.90 \%$ & $11.50 \%$ & 89 & 1830 & $4.86 \%$ & 0.2 \\
\hline 3 & 10 & 50 & 10 & 4 & $40 \%$ & $40 \%$ & 200 & $96.60 \%$ & $11.50 \%$ & 122 & 1830 & $6.67 \%$ & 0.2 \\
\hline 4 & 10 & 100 & 10 & 4 & $40 \%$ & $40 \%$ & 200 & $91.10 \%$ & $18.50 \%$ & 232 & 6105 & $3.80 \%$ & 0.1 \\
\hline 5 & 50 & 100 & 10 & 4 & $40 \%$ & $40 \%$ & 200 & $84.60 \%$ & $30 \%$ & 1428 & 11026 & $12.95 \%$ & 0.5 \\
\hline
\end{tabular}

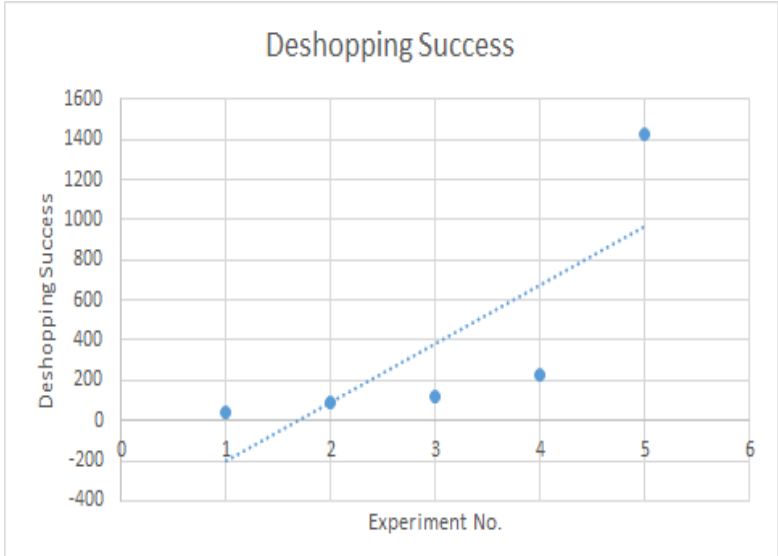

Fig 2: Deshopping success in simulation runs

\section{CONCLUSIONS}

The multi-agent simulation model created in the paper demonstrates the impact of deshopping and the dilemma of retail businesses with return policies. From the experiment we have observed that deshopping requires further awareness from businesses and regulatory bodies due to its consequences. This will be of interest to both practitioners and academics of deshopping research, retail crime research, marketing management, supply chain and strategic management. Our model integrates the benefits of various methods, techniques and technologies for representing, simulating and analyzing deshopper behavior. Such a model will help managers understand deshoppers and consumers through relevant framework, processes and tools, and will be of great operational and strategic importance to companies for scenario-based analysis. In addition, the model draws attention to the general state of deshopping in retail marketing arena, and provides a solid foundation for further research and development.

\section{ACKNOWLEDGMENT}

The software package used in this simulation study is Netlogo provided by Northwestern University, USA.

The publication of this paper is financially supported by the University of Westminster (UK) staff research allowances, and the Sichuan 100-Talent Scheme Award that is hosted by Southwest Jiaotong University, China.

\section{REFERENCES}

[1] S. S. Rahman and S. Li, "A Hybrid Framework for Modeling and Simulation for Deshopping Behaviour and How Companies Respond", Proceedings of the 3rd International Conference on Energy Systems, Environment, Entrepreneurship and Innovation, WSEAS, pp.176-181, 2014.

[2] T. King, C. Dennis and L. Wright, "Customer returns and the theory of planned behaviour", Journal of Marketing Management, Vol.24, No.1-2, pp.185-203, 2008.

[3] O. Roozmand, G. Nasser, G., Hofstede, M. Nematbakhsh, A. Baraani and T. Verwaart, "Agent-based modeling of consumer decision making process based on power distance and personality", Knowledge-Based Systems, Vol.24, pp.1075-1095, 2011.

[4] D. Strutton, L. Pelton and O. Ferrell, "Ethical behavior in retail settings: is there a generation gap?", Journal of Business Ethics, Vol.16, pp.87$105,1997$.

[5] C. Harris, "Fraudulent Return Proclivity: An Empirical Analysis", Journal of Retailing, Vol.84, No.4, pp.461-476, 2008.

[6] D. Rogers and R. Tibben-Lembke, "Going Backwards: Reverse Logistics Trends and Practices", Reverse Logistics Executive Council, 1998.

[7] R. Schmidt, F. Sturrock, P. Ward and G. Lea-Greenwood, "Deshopping: The Art of illicit consumption", International Journal of Retail \& Distribution Management, Vol.27, No.8, pp.290-301, 1999.

[8] T. Zhang and D. Zhang, "Agent-based simulation of consumer purchase decision-making and the decoy effect", Journal of Business Research, 60, 912-922, 2007.

[9] M. Rosenbaum, R. Kuntze and B. Woodridge, "Understanding unethical retail disposition practice and restraint from the consumer perspective", Psychology \& Marketing, Vol.28, No.1, pp.29-52, 2011.

[10] R. Skapa, "Application of the theory of planned behaviour to fraudulent returning", Acta univ. Agric. Et silvic. Mendel. Brun., lx, No.7, pp.379-386, 2012.

[11] C. Yu and C. Wang, "A hybrid mining approach for optimizing returns policies in E-retailing", Expert Systems with Applications, Vol.35, No.4, pp.1575-1582, 2008. 
[12] T. King, An Analysis of the Phenomenon of Deshopping of Garments in Women's Wear Retailing, Unpublished PhD. Thesis, Brunel: Brunel University, 2004.

[13] T. King, C. Dennis and J. Mchendry, "The management of deshopping and its effects on service: a mass market case study", International Journal of Retail and Distribution Management, Vol.35, No.9, pp.720733, 2007.

[14] T. King and C. Dennis, "Interviews of Deshopping Behaviour: an Analysis of Theory of Planned Behaviour", International Journal of Retail and Distribution Management, Vol.31, No.3, pp.153-163, 2003.

[15] M. Ahmed and M. Latif, M., "Exploiting Simulation for Product Returns in SMEs", Proceedings of the World Congress on Engineering, Vol III, 2010.

[16] I. Ajzen, "From Intention to action: a theory of planned behaviour", In: Kuhl J and Beckman J (eds.), Action Control: From Cognitions to Behaviours, New York, Springer, 1985.

[17] M. Fishbein and I. Ajzen, Belief, attitude, intention, and behaviour, An introduction to theory and research. Reading, MA: Addison-Wesley, 1975.

[18] M. Rosenbaum and R. Kuntz, "The relationship between anomie and unethical retail disposition", Psychology \& Marketing, Vol.20, No.12, pp.1067-1093, 2003.

[19] M. Rosenbaum, R. Kuntze and B. Woodridge, "Understanding unethical retail disposition practice and restraint from the consumer perspective”, Psychology \& Marketing, 28(1), 29-52, 2011.
[20] J. Engel, R. Blackwell and P. Miniard, Consumer Behaviour, 8th ed. Philadelphia: The Dryden Press, 1995.

[21] T. Zhang and D. Zhang, "Agent-based simulation of consumer purchase decision-making and the decoy effect", Journal of Business Research, Vol.60, pp.912-922, 2007.

[22] V. Mitchell, G. Balabanis, B. Schlegelmilch and T. Cornwell, "Measuring Unethical Consumer Behavior across Four Countries", Journal of Business Ethics, (88), 395-412, 2009.

[23] S. Muncy and J. Vittell, "The Consumer Ethics Scale: A Modification and Application", Journal of Business Ethics, , 62, 267-275, 2005.

[24] J. Holland and J. Miller, "Adaptive agents in economic theory", The American economic review, 81(2), 365-370, 1991.

[25] J. Holland, "Studying complex adaptive systems", Jrl Syst Sci \& Complexity, 19, 1-8, 2006.

[26] S. Li, "An Integrated Approach to Flexible Modelling and Animated Simulation", Journal of Southwest Jiaotong University (English version, ISSN1005-2429), 2(2), 119-125, 1994.

[27] I. Ajzen, "The Theory of Planned Behaviour", Organisational Behaviours and Human Decision Processes, Vol.50, pp.179-211, 1991.

[28] J. Holland and J. H. Miller, "Adaptive agents in economic theory", The American economic review, Vol.81, No.2, pp.365-370, 1991.

[29] J. Holland, "Studying complex adaptive systems", Jrl Syst Sci \& Complexity, Vol.19, pp.1-8, 2006. 